\title{
Toward a Taxonomy of Loanword Prosody
}

\author{
Stuart Davis \\ Indiana University. Department of Linguistics \\ davis@indiana.edu
}

\section{Natsuko Tsujimura}

Indiana University. Department of East Asian Languages and Cultures

tsujimur@indiana.edu

\section{Jung-yueh Tu}

Indiana University. Department of Linguistics

jutu@indiana.edu

\begin{abstract}
Building on previous works (e.g. Kubozono 2006, and Kang 2010), this article attempts to establish a taxonomy for loanword prosody, referring specifically to the patterns of stress, tone, or pitch-accent that are found in loanwords. Toward a taxonomy, we consider the following factors: (i) whether the pronunciation of the word in the source language influences the assignment of prosody in the borrowing language; (ii) whether prosody assignment is aided by rules (or constraints) that are specific to loanwords; and (iii) whether segmental features or suprasegmental features play a role. Exemplification of languages instantiating the taxonomy will be provided with discussion regarding issues that arise from the proposed taxonomy.
\end{abstract}

Keywords: loanword; prosody; taxonomy.

\section{Table of Contents}

\section{Introduction}

2. English loanword stress in Modern Hebrew (nouns)

3. Mandarin and English loanwords in Lhasa Tibetan

4. English loanwords in Cantonese

5. Japanese loanwords in Taiwanese Southern Min (TSM)
6. English loanwords in standard (Tokyo) Japanese

7. English loanwords in North Kyungsang Korean (NKK)

8. English loanwords in South Kyungsang Korean (SKK)

9. Summary and discussion

Acknowledgement

References 


\section{Introduction}

Much research on loanword phonology has focused on issues of segmental adaptation while its prosodic aspect has received relatively less attention in the literature (cf. Kang 2010). Languages exhibit a variety of ways in which prosodic prominence is marked (e.g. stress, tone, pitch-accent), but when words in one language are borrowed into another language and the two languages do not share the same suprasegmental system, it raises a linguistically interesting question as to whether and how the two languages negotiate the difference in prosodic systems. The factors that are at play in assigning word prosody to loanwords are quite different from those involved in segmental adaptation (see Kang 2011 for a recent overview). One reason for this difference is that even if speakers can accurately perceive the location of stress or accent of a source word, there may be no direct way to interpret it if the prosodic system of the borrowing language is very different. For example, as observed by Kang (2010), stress is a syntagmatic property, which is signaled by a combination of pitch, intensity, and duration (see Cutler 2005 for pertinent discussion), whereas tone is a paradigmatic property, which has $\mathrm{f}_{0}$ as a direct phonetic correlate. Furthermore, even if we follow Hyman (2006) in viewing pitch-accent as not a separate system of word prosody (but perhaps as a subtype of tone), the relevant characteristics of pitch-accent languages (e.g. standard Japanese and Kyungsang Korean) and tone languages (e.g. the different Chinese languages) can still be different enough to preclude a straightforward means of prosodic accommodation based on phonetic or perceptual properties alone. It is in such cases that a language needs to develop a strategy to assign prosody to loanwords.

In her extensive survey of prosodic adaptation reported in a number of languages, Kang (2010) discusses the degree to which the prosodic system of the source language is taken into consideration in loanword adaptation, pointing out a contrast between stress languages on the one hand and tone and pitch-accent languages on the other as a borrowing language. It is important to accurately describe and explain how prosodic adaptation is accommodated when different suprasegmental systems are involved in the borrowing, as has already been attested to in the literature (e.g. Kenstowicz \& Sohn 2001; Kim 2009; Kubozono 2006; Lee 2005, 2009; Tu \& Davis 2009; Kang 2010). Also as Broselow (2009) observes, issues of prosodic adaptation come up even when suprasegmental type is similar, as when stress is characteristic of both source and borrowing languages. Equally important, from a typological perspective, is to reach a coherent classification of factors that are considered (or available) in accommodating differences between two prosodic systems relevant to loanwords, so that deep-rooted principles underlying the classification would lead us to a better understanding of the nature of prosodic adaptation in the loanword process. With the establishment of a taxonomy of loanword prosody as our ultimate (and long-term) goal, this article offers a first estimation of organizing into a taxonomy different factors that languages use to assign word prosody to loanwords. Based on seven cases of loanword prosody patterns encompassing Japanese, Lhasa Tibetan, two dialects of Korean-South and North Kyungsang Korean- 
Hong Kong Cantonese, Taiwanese Southern Min, and Modern Hebrew, we have initially identified at least three factors that contribute to a taxonomy of prosodic adaptation: first, whether features of the source language are taken into consideration for the assignment of prosody in the borrowing language; second, whether prosody assignment to borrowed words is aided by rules (or constraints) that are specific to loanwords; and third, whether segmental features or suprasegmental features (including syllable type) play a role in the adaptation. While these factors are mentioned by Kang (2010), our goal is to develop a taxonomy of loanword prosody built around them. These three factors map the seven language samples to the taxonomy below, with the abbreviated labels for each factor:

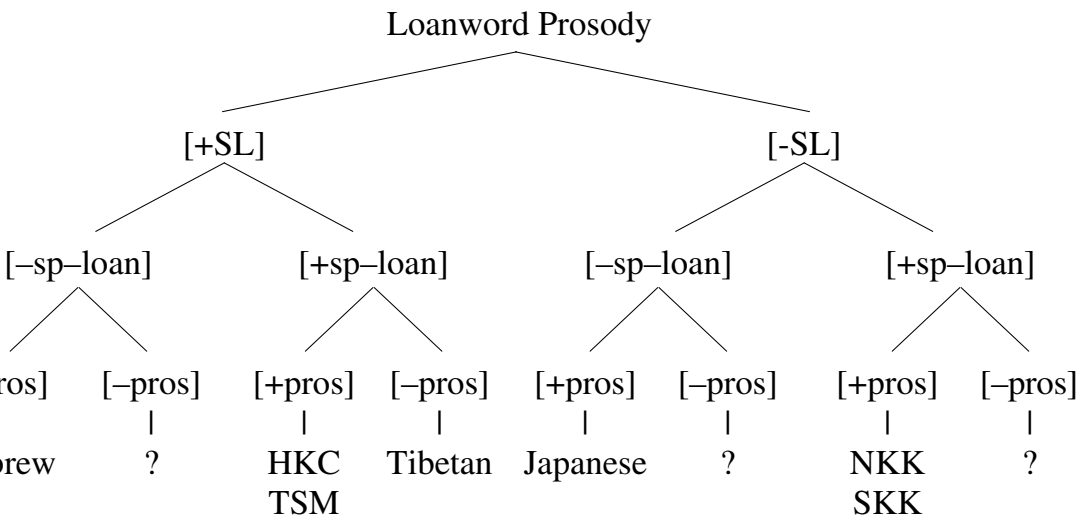

[+/-SL]: [+/-source language]

[+/-sp-loan]: [+/-specific to loanwords]

[+/-pros]: [+/-prosody]

HKC: Hong Kong Cantonese

TSM: Taiwanese Southern Min

NKK: North Kyungsang Korean

SKK: South Kyungsang Korean

In Sections 2-5, we will present languages in which characteristics of the source language influence prosodic adaptation; and in Sections 6-8, we discuss cases where the source language does not seem to have such an influence. Section 9 further discusses issues that emerge from the proposed taxonomy, offering directions for future research. 


\section{English loanword stress in Modern Hebrew (nouns)}

Loanwords in Modern Hebrew-here we focus exclusively on nouns 1 — provide a case in which the stress location of the source language is typically preserved. We base our discussion on works by Becker (2003), Graf and Ussishkin (2003), and Bat-El (2005). Most Hebrew nouns have stress on the final syllable. If a suffix is added, such as the plural, stress will shift to the suffix. This class is referred to as mobile stress by Becker (2003) and Bat-El (2005) and is exemplified by the data in (2).

(2) Mobile final stress
Singular
Plural
Gloss
a. xút
xut-ím
string
b. tavlín
tavlin-ím
spice
c. matan-á
matan-ót
gift (f.)
d. melafefón
melafefon-ím
cucumber

A second and much smaller class of native Hebrew nouns consists of words where stress on the penultimate syllable in the (unaffixed) singular shifts to the final syllable in suffixal forms. The examples in (3) are taken from Bat-El (2005: 120), who labels this class mobile penultimate stress.

(3) Mobile penultimate stress

$\begin{array}{lll}\quad \text { Singular } & \text { Plural } & \text { Gloss } \\ \text { a. nékev } & \text { nekav-ím } & \text { hole } \\ \text { b. xéder } & \text { xadar-ím } & \text { room } \\ \text { c. } \text { } \text { óre } & \text { Joraf-ím } & \text { root }\end{array}$

In addition to mobile stress on nouns, Modern Hebrew has developed a class of nouns that has immobile stress. That is, in these nouns, stress does not shift to the final syllable when a suffix is added. The nouns in this class are in some sense marginal including acronym words, slang, proper nouns, blends, and some reduplicated nouns. There are also more normative words in this class whose immobile plural may have originated to avoid homophony (see Zuckermann 2003: 12). Examples are shown in (4).

1. While loan forms can appear as verbs in Modern Hebrew, there is typically root (or stem) extraction of the loan consonants (and sometimes vowels) so as to make the loan form fit into the templatic morphology of the verbal system where there is a predictable pattern of stress. For example, the borrowing of the English noun code [kód] can be made into the verb [kodéd] ('to codify') whose shape and stress is determined by a verbal template (see Bat-El 1994 and Ussishkin 1999 for details and analysis). 
(4) Immobile stress Singular
Plural
Gloss
a. rasáp
rasáp-im
company sergeant (acronym from [rav samal plugati])
b. sabón
sabón-im
nerd (nonslang: sabón/sabon-ím 'soap')
c. jónatan
jónatan-im
(personal name)
d. kàdursál
kàdursál-im
basketball (blend from [kadur] 'ball'+[sal] 'basket' — see Bat-El 1996)
e. mífmif
mífmif-im
apricot
f. pán
pán-im
aspect, form (compare with [paním] 'face')

Immobile stress on nouns seems to be an innovation of the modern language and was not recorded as occurring in Tiberian Hebrew, the biblical language (Michael Becker, p. c.). The development of immobile stress may have been largely influenced by the European source languages (especially Yiddish and Slavic) that affected Modern Hebrew and was most likely present from the very beginning of the modern language (see Zuckermann 2003). To summarize so far, there are three classes of nouns with respect to stress in Modern Hebrew: (i) the most frequent mobile final class, (ii) the mobile penultimate class, and (iii) the immobile class, which is an innovation of the modern language.

Analyses such as Bat-El (2005) consider the mobile final class in (i)—exemplified in (2) — as being unmarked, i.e. not lexically marked. On the other hand, nouns with immobile stress in (iii)_exemplified in (4)_ are lexically marked for stress on specific syllables. Bat-El's optimality-theoretic analysis entails that faithfulness to lexical stress outranks the constraints that favor final stress. The unmarked status of the mobile final class, she argues, is supported by language acquisition evidence. When young children have acquired a sufficient number of nouns, there is a certain degree of overgeneralization on suffix forms applied to the immobile class. She suggests that the overgeneralization is statistically motivated because most nouns take mobile stress. As for the mobile penultimate class in (ii)-exemplified in (3) - Bat-El proposes that these nouns are also lexically unmarked for stress, but the singular forms are indexed to a special constraint ranking that favors penultimate stress.

Turning to loanwords in Modern Hebrew, almost all the source languagesmainly European languages and Arabic - mark their prosodic prominence by stress. We first note that the source language plays a significant role in that the suprasegmental property of stress is directly borrowed, preserving the stress location. This is illustrated in (5), in which the location of stress is identical between the English source and its Hebrew form. 
(5)

$\begin{array}{ll}\text { English } & \text { Modern Hebrew - singular } \\ \text { a. dóctor } & \text { dóktor } \\ \text { b. ámbulance } & \text { Pámbulans } \\ \text { c. univérsity } & \text { Punivérsita } \\ \text { d. cópywriter } & \text { kópirayter } \\ \text { e. géne } & \text { gén }\end{array}$

Furthermore, the loanword stress does not shift when suffixes are added, as in (6): this follows the immobile stress class of (iii).
Singular
Plural
a. dóktor
dóktor-im
b. Pámbulans
Pámbulans-im
c. Punivérsita
Punivérsit-ot
d. kópirayter
kópirayter-im
e. gén
gén-im

These plural loanword forms and Modern Hebrew native words in (4) share the same property that suffixation does not influence the stress of the root. That is, the suffixed loanwords in (6) make it clear that the direct borrowing of source stress in (5) does not create an independent prosodic pattern unique to loanwords; instead, the plural suffixation reveals that the stress assignment on loanwords in fact comes from the native immobile stress pattern. The loanword prosody, thus, adopts one of the stress patterns that is already available in Modern Hebrew, incorporated in the prosodic system of the borrowing language although this is a minority pattern within the langauge. While our discussion has focused on English as the probable source language, it is known that loanwords in Modern Hebrew from other languages like Arabic and Slavic languages also take the same pattern of immobile stress. (Zuckermann 2003): e.g. [xamsín] - [xamsínim] ('heat wave') comes from Arabic.

The characteristics pertinent to our taxonomy are summarized in (7).

(7) a. The prosodic system of the source language plays a role. [+SL]

b. The prosody assignment to loanwords follows one of the native prosodic patterns, and is not specific to loanwords. [-sp-loan]

c. Suprasegmental, and not segmental, features play a role. [+pros]

\section{Mandarin and English loanwords in Lhasa Tibetan}

The borrowing of words from Mandarin Chinese (tone language) and from English (stress language) into Lhasa Tibetan has been discussed in detail by Hsieh and Kenstowicz (2008) and Kang (2010). An immediate question arises as to whether 
borrowings from these two source languages-a tone language and a stress language-take different strategies. It will be shown that the source language plays a significant role in loanword prosody, but that interestingly the contribution of the two different source languages is similar in that segmental, rather than prosodic, properties influence the realization of tone in word borrowing.

Lhasa Tibetan has contrastive tone (high tone vs. low tone) only on the initial syllable of words; all other syllables have high tone. As discussed by Hsieh and Kenstowicz (2008) and Kang (2010), when Mandarin is the source language, its tone is entirely ignored in the process of tone assignment on the initial syllable in Tibetan. Instead, Mandarin words that begin with (voiceless) obstruents are borrowed in Tibetan with high tone on the initial syllable while those with initial sonorants are borrowed with low tone on that syllable. According to Hsieh and Kenstowicz, a similar pattern is observed when the source language is English. When an English word begins with a voiceless consonant, its Tibetan counterpart is assigned an initial high tone, and an English word beginning with a voiced sound will be borrowed with an initial low tone. The contrast is shown in (8).
$\mathrm{H} \quad \mathrm{H} \quad \mathrm{H}$
$\mathrm{L} \mathrm{H} \mathrm{H}$
a. políce $\rightarrow p u$ li su
b. bóttle $\rightarrow$ po to ra

These two examples are particularly relevant because they show a mismatch between the pitch pattern on the source words in English and the way in which the borrowed words receives pitch. In (8a), the lower pitch associated with the unstressed initial syllable of the source word police is realized with the high pitch in Tibetan. In (8b), the initial syllable of bottle is stressed with high pitch in English, but the borrowing counterpart ends up with low pitch. These examples demonstrate that the source language is taken into consideration to the extent that the nature of the initial segment of the source word contributes to the tone assignment in the borrowing language. Notice that in Tibetan, the examples in (8a) and (8b) have the same initial consonant.

Hsieh and Kenstowicz further note that the pattern found with English and Mandarin loans does not seem to be typical of native Tibetan words. It suggests that the prosodic assignment that is sensitive to the nature of the initial segment of the words in the source language does not follow any synchronic native prosodic pattern but is unique to the class of loanwords.

The borrowing pattern in Tibetan can be understood as having a phonetic basis: there are both aerodynamic and physiological reasons as to why a vowel immediately following a voiceless consonant may be associated with higher pitch and one after a voiced consonant (obstruent) would have lower pitch (see, for example, Hombert et al. 1979). Furthermore, Kingston and Diehl (1994) suggest that this pitch distinction may be enhanced in languages in which the feature [voice] plays a role in phonemic contrasts so as to make the contrast more perceptually distinct. These pitch differences can be significant in tonogenesis (Kingston 2011) where the loss of a voicing contrast in obstruents results in the occurrence of a phonemic tonal 
contrast whereby syllables with a historically voiceless obstruent develop a phonemic high tone. Crucially, the strategy employed by Tibetan is an abstract strategy because it ignores the overall pitch pattern of the source word. In the borrowing, the source suprasegmental properties, be it Mandarin tone or English stress, are ignored although attention is paid to the source segments; and tone is independently assigned to loanwords based on voicelessness, which is subsequently manifested as high pitch. Thus, the strategy used by Lhasa Tibetan in assigning tone to the initial syllable of a loanword is underlyingly phonetic in nature.

Based on our three factors, the prosodic pattern in Tibetan loanwords is summarized in (9).

(9) a. The segmental nature of the source language plays a role although its prosodic system is not relevant. [+SL]

b. The prosody assignment to loanwords is specific to loanwords. [+sp-loan]

c. The segmental, and not suprasegmental, features of source words play a role. [-pros]

\section{English loanwords in Cantonese}

The accommodation of English stress into Hong Kong Cantonese (HKC) has been a familiar case in the literature on loanword phonology (Silverman 1992; Yip 1993). As with Hebrew and Tibetan, HKC makes reference to the source language, but presenting a stress-to-tone mapping. $\mathrm{HKC}-\mathrm{a}$ tone language-has a large number of loanwords from English due to the period of British colonization. The language has six non-checked tones, ${ }^{2}$ including a high level tone, a highrising tone, a mid level tone, a low-falling tone, a low-rising tone, and a low level tone. Additionally, it has three checked tones, which fall on the syllables ending in stops and are shorter in duration, including high, mid, and low checked tones (Bauer \& Benedict, 1997).

Previous studies have drawn some generalizations on the English borrowings into HKC (e.g. Kiu 1977; Silverman 1992; Hao 2009). The stressed syllable in English - both primary and secondary - usually carries a high tone in HKC. For example, the English word beat is adapted as [pit] $(\mathrm{H})$ and saxophone as [sik si: fun] (H.LL.HH), where high tones are on the first and last syllables corresponding to initial primary and final secondary stress. That is, HKC pays close attention to the suprasegmental properties of source words in that stressed syllables in English are uniformly adapted to the high tone in HKC. Importantly, all English-based loanwords have high tone, but this is not characteristic of native $\mathrm{HKC}$ words since many HKC words lack high tone, given its tonal inventory mentioned above. That is, tone in native $\mathrm{HKC}$ words is arbitrary and lexicalized. So, the adaptation of

2. A non-checked tone is a tone on a bimoraic syllable ( $\mathrm{CVV}$ or CVN). A checked tone is a tone on a light syllable including a syllable closed by an obstruent. The terms 'entering' tone and 'nonentering' tone are also used for checked and non-checked tones, respectively. 
English stress to HKC high tone is specific to loanword prosody in this language. Put differently, one can view English loanwords as being required to have high tone, a requirement that is specific to the (English) loan phonology.

For the adaptation of unstressed syllables in English, a pretonic unstressed syllable is assigned a mid tone while a post-tonic unstressed syllable is assigned a low tone. This is exemplified by the word assignment borrowed as [a: saj mən] (MM. HH.LH). ${ }^{3}$ The prosodic mapping from English to HKC is essentially processed in a syllable-to-syllable fashion. Every English syllable receives a predictable tone in HKC. As we shall see in section 5, this will be contrasted with the case in Taiwanese Southern Min. The mapping of English stress to HKC high tone may be straightforwardly explained in phonetic terms: the high pitch of English stress correlates with HKC high tone. ${ }^{4}$ Consequently, HKC presents a good example of a phonetic strategy in loanword prosody that matches the higher pitch of the English stress syllable with a high tone realization on the corresponding syllable in the loanword.

The relevant properties for the taxonomy are summarized in (10).

(10) a. The prosodic system of the source language plays a role. [+SL]

b. The prosody assignment to loanwords is specific to loanwords. [+sp-loan]

c. Suprasegmental, and not segmental, features play a role. [+pros]

d. Additionally, adaptation is syllable-to-syllable.

\section{Japanese loanwords in Taiwanese Southern Min (TSM) ${ }^{5}$}

The borrowing of Japanese words into Taiwanese Southern Min (TSM) presents a situation in which prosodic adaptation takes place from a pitch-accent language (Japanese) to a language with a complex tone system (TSM). ${ }^{6}$ In a pitch-accent system like standard Japanese, once the location of the accented mora (or syllable) is known, then the pitch pattern of the entire word is predictable. In standard

3. As this example shows, some loanwords take a final high tone so that the last syllable is rising. Silverman (1992) suggests that the final H reflects a boundary tone. Michael Kenstowicz (p. c.) suggested to us that this could be a manifestation of what is referred to as pinjam or 'changed tone' in the Cantonese linguistics literature. As discussed by Yu (2007), the final $\mathrm{H}$ creating a rising tone occurs in certain morphological contexts in Cantonese including the nominalization of verbal action and denotation of familiar or diminutive objects. Yu, however, does not discuss its possible application to loanwords.

4. Furthermore, it can be suggested that the assignment of mid tone to a pretonic syllable and low tone to a post-tonic syllable has a basis in the perception of English word intonation.

5. The analysis of Japanese loanwords into TSM that we offer here is conceptually very different from Hsieh (2006) and Kang (2010), in which various Japanese rhyme types are assigned specific tones with subsequent application of tone sandhi rules, some of which are specific to Japanese loanwords. See Tu (forthcoming) for discussion.

6. Japanese loanwords into TSM are interesting in light of the fact that there was a long period of contact between the two languages in the first part of the 20th century with bilingualism among many Taiwanese during the Japanese colonial period, 1895-1945. 
Japanese (e.g. Haraguchi 1977), when a mora is associated with accent, all moras after it have low pitch while the accented mora and all preceding moras receive high pitch. Furthermore, the initial unaccented mora is assigned low pitch due to the Initial Lowering Rule (Haraguchi 1977). An unaccented word in Japanese surfaces with an initial low tone, again as a result of the Initial Lowering Rule, followed by a sequence of high tones without pitch fall.

TSM is one of the Chinese languages that is well known for the one-morphemeper-syllable tendency; that is, each syllable has a particular tonal value associated with it. The number of tones in TSM is still controversial without a clear consensus. Most linguists, however, agree on seven (Chen 1987; Cheng 1979; Chung 1996), including five non-checked tones $(\mathrm{H}, \mathrm{M}, \mathrm{L}, \mathrm{LM}, \mathrm{HL})$ and two checked tones $(\mathrm{h}$, $\mathrm{m}){ }^{7}$ which occur in syllables closed by obstruents. Based on this, we will assume that in TSM a syllable closed by a sonorant is bimoraic while a checked syllable closed by an obstruent is monomoraic (Zhang 1998).

In (11), we present some examples of Japanese loanwords into TSM. It appears that the pitch pattern on individual Japanese words is not maintained in the borrowing into TSM. That is, a high pitch on a Japanese mora does not guarantee that the corresponding syllable is realized with a high tone in TSM.

(11) Japanese loanwords into $\mathrm{TSM}^{8}$ (Hsieh 2006; Tu \& Davis 2009)

\begin{tabular}{|c|c|c|c|c|}
\hline Japanese & & Taiwanese & & Gloss \\
\hline a. pan & $H \mathrm{~L}$ & $\mathrm{p}^{\mathrm{h}}$ ay & $H \mathrm{~L}$ & bread \\
\hline b. sushi & $\mathrm{L} H$ & su.ci? & $H \mathrm{~m}$ & sushi \\
\hline c. kaban & $\mathrm{LHH}$ & $\mathrm{k}^{\mathrm{h}} \mathrm{a} \cdot \mathrm{ba \eta}$ & $\mathrm{M} H \mathrm{~L}$ & bag \\
\hline d. kanpai & LHHH & $\mathrm{k}^{\mathrm{h}}$ am.pai & $\mathrm{MH} H \mathrm{~L}$ & to toast \\
\hline e. oden & $\mathrm{L} H \mathrm{~L}$ & o.len & $\mathrm{M} H \mathrm{~L}$ & oden (Japanese dish) \\
\hline sashimi & $\mathrm{LH} H$ & sa. ci.mi? & $\mathrm{MH}$ & sashimi \\
\hline g. wasabi & $H \mathrm{LL}$ & wa.sa.bi? & $\mathrm{MH} \mathrm{m}$ & mustard \\
\hline h. obaasan & LHLLL & o.ba.san & M H HL & old woman \\
\hline misoshiru & $\mathrm{LH} H \mathrm{~L}$ & mi.so.ci.lu? & M H $H \mathrm{~m}$ & miso soup \\
\hline bakkumiraa & LHHLL & bak.k ${ }^{\mathrm{h}}$ u.mi.la? & $\mathrm{m} \mathrm{HH} \mathrm{m}$ & side mirrors \\
\hline k. handoru & LHHH & han.to.lu? & $\mathrm{MH} H \mathrm{~m}$ & steering wheel \\
\hline aisatsu & HLLL & ai.sa.tsu? & $\mathrm{MH} H \mathrm{~m}$ & greeting \\
\hline m. pachinko & LHHH & $\mathrm{p}^{\mathrm{h}}$ a.t ${ }^{\mathrm{h}}$ in.ko? & $\mathrm{M} H \mathrm{~L} \mathrm{~m}$ & pachinko \\
\hline n. bansookoo & LHHНHH & ban.soo.ko? & $\mathrm{MH} H \mathrm{~L} \mathrm{~m}$ & Band-Aid \\
\hline o. $\operatorname{tansu}$ & LHH & $\mathrm{t}^{\mathrm{h}}$ ay.su? & $H \mathrm{~L} \mathrm{~m}$ & chest of drawers \\
\hline
\end{tabular}

7. Checked tones are indicated with lower case in this section.

8. In (11) the Italicized $\mathrm{H}$ for Japanese words indicates the accented mora. If no Italicized $\mathrm{H}$ is shown, the word is unaccented. In the TSM tonal data a space between tones indicates that the tones are realized on separate syllables; the rightmost $\mathrm{H}$ tone is indicated in Italics. 
Example words illustrating that the Japanese pitch pattern is not maintained in the TSM borrowing include the word tansu (110), which in Japanese has the LHH pattern, but this pitch sequence is realized as a falling tone (HL) on the first syllable and a mid checked tone on the second in TSM. Furthermore, wasabi in (11g) has the pattern HLL in Japanese, but it is borrowed with the MHm pattern.

The tone assignment on the Japanese loanwords in TSM does not seem to have a generalizable pattern that references the pitch of the specific words in the source language. A closer examination, however, reveals that there is basically only one tone pattern on the TSM form pertinent to the prosodic assignment of loanwords, making it totally predictable (Tu \& Davis 2009), and that the source language does play a role in such a unique tone assignment. To see the relevant pattern more clearly, let us focus exclusively on the TSM loanwords on the righthand column in (11). In longer words of (11c-n), the loanwords are characterized by an initial rise, from $\mathrm{M}$ to $\mathrm{H}$, with high tone until the penultimate syllable or mora, followed by a final fall. ${ }^{9}$ In shorter words of (11a-b), there is only a final fall. Furthermore, it is crucial to note that the $\mathrm{MH}$ tone in the initial syllable, as is exemplified in the loanwords in $(11 \mathrm{~d}, \mathrm{k}, \mathrm{l})$, is not found on single syllables of native TSM words. The melody consisting of $\mathrm{M}$ to $\mathrm{H}$ followed by a fall, then, is a predictable prosodic pattern specific to the loanword class in TSM. An immediate question arises as to where such a melody comes from. It is not a characteristic of TSM native words. As Tu (forthcoming) argues, the melody reflects an attempt to adopt Japanese word prosody in a general way: since many Japanese words are accented with a pitch fall, the TSM loanword melody discussed above can be interpreted to draw a parallelism to the Japanese accent system using the mechanisms of the TSM tonal system. It is noteworthy that this melody-based tonal assignment is not characteristic of any native TSM words.

The TSM system of loanword adaptation can thus be understood as an attempt to adopt the global property of the intonation pattern of Japanese words, i.e. as melody, without necessarily being faithful to the individual pitch manifested on each mora of the Japanese source word. We can characterize the adaptation pattern as melody-to-melody mapping. This contrasts with the case in $\mathrm{HKC}$, where the prosodic assignment is captured as syllable-to-syllable mapping. ${ }^{10}$

9. Note that the rightmost high tone normally occurs on the penultimate mora unless that mora is a sonorant consonant, or the second part of a long vowel or diphthong. In such a case, the high tone goes on the antepenultimate mora, $(11 \mathrm{n}, \mathrm{o})$. Furthermore, if the final mora of the TSM form constitutes a checked syllable, then that syllable will have mid tone since TSM does not allow for low tone on a checked syllable, at least according to most descriptions.

10. English borrowings into HKC and Japanese borrowings into TSM both represent instances of borrowing that occurs as a result of long term contact and bilingualism of many speakers. What then leads to the difference between the syllable-to-syllable mapping of English stress to HKC tone versus the melody-to-melody mapping of Japanese pitch-accent to TSM tone, where the specific pitch on source syllables can be ignored? We suggest that this difference resides in the wide range of accentuation patterns observed in various dialects of Japanese, to which TSM speakers must have been exposed during the colonial period. We conjecture that the melody type of an initial rise with a final fall may have come to be the most standard way of perceiving Japanese words by TSM speakers. On the other hand, English stress patterns are quite uniform across dialects. 
The properties pertinent to loanword prosody in TSM are listed in (12).

(12) a. The prosodic system of the source language is taken into consideration as a basis for the tonal melody of TSM. [+SL]

b. The prosody assignment to loanwords is specific to loanwords. [+sp-loan]

c. Suprasegmental, and not segmental, features play a role. [+pros]

d. The prosodic adaptation is processed melody-to-melody.

\section{English loanwords in standard (Tokyo) Japanese}

English is a stress language while Japanese is a pitch-accent language; in the adaptation of English stress into Japanese, source words with stress have to be assigned a pitch accent. Consider the three examples: waSHInton 'Washington', BAnana 'banana', and GUrasu 'glass'. ${ }^{11}$ The English word Wáshington has stress on the first syllable, but the accentuation in Japanese is on the second mora. The English banána with stress on the second syllable is borrowed into Japanese with the accent on the initial syllable. The English gláss is borrowed as GUrasu with accent on the first mora, where the vowel $[\mathrm{u}]$ is inserted to break up a consonant cluster [gl] in the English source. The difference in location of stress in English and accent in Japanese is puzzling in light of the fact that the Japanese accentuation system can accommodate both initial and second syllable accent since there are native Japanese nouns with such accentual patterns. Furthermore, it is not that Japanese speakers are unable to perceive English stress: as Altmann (2006) shows, Japanese speakers perform like English native speakers with respect to the perception of English stress. It seems clear then that the suprasegmental property of the source language, i.e. English, does not play a role in the prosody assignment of loanwords in Japanese.

In order to capture the accentuation pattern of loanwords, McCawley (1968) draws the generalization that loanword accent is on the syllable containing the antepenultimate mora. This generalization accounts for the accent pattern of an extensive range of data that include the examples above, wa.SHIn.ton, BAnana, and $G U$.ra.su. Japanese native nouns display more options for the location of lexical accent beyond the syllable containing the antepenultimate mora, such as initial, second, penultimate, final, and unaccented. In light of a variety of potential accent locations available to the borrowing language, McCawley's generalization may be viewed to be applicable only to loanwords. Kubozono (2006, 2011), however, insightfully relates it to the most common accent patterns found in native Japanese nouns. Noting that the majority of Japanese nouns are unaccented while almost all borrowed English words are accented, Kubozono demonstrates that accentuation on the syllable containing the antepenultimate

11. The mora indicated in Italics and upper case in these three examples is pronounced with a high pitch; the other moras or syllables are pronounced with a low pitch. The accented syllable or mora in Tokyo Japanese is the one that is immediately followed by a pitch fall (i.e. low pitch). 
mora is indeed the most common pattern found among accented native Japanese nouns. That is, McCawley's generalization regarding loanword accent actually follows the most frequent accent pattern available to native words, at least to accented native nouns. ${ }^{12}$

Capturing loanword accentuation by referencing the most common pattern of the borrowing language, Kubozono $(2006,2011)$ goes on to show that the accentuation pattern in question is even more generally characterized in terms of foot structure: accent falls on the head of the rightmost nonfinal (trochaic) foot. This analysis is argued by Kubozono to help explain the accentuation of Japanese compound nouns. The footing in (13)-(14) uniformly places the accent of the compounds, (13), and loanwords, (14), on the head of the non-final foot. From a perspective of constraint satisfaction, the foot structure of (13)-(14) satisfies an edgemostness constraint that puts accent maximally toward the right edge of the word while also respecting nonfinality so that the head foot is not aligned with the right edge of the word. See Kubozono (2006, 2011) for details.

$$
\begin{aligned}
& \text { a. } Y A \text { mato }+ \text { na } D E \text { siko } \rightarrow \text { yamato-na( } D E \text { si)ko } \quad \text { ('Japanese lady') } \\
& \text { b. ya } M A+\text { otoKO } \rightarrow \text { yama-(Oto)ko ('mountaineer') }
\end{aligned}
$$
a. wa(SHIn)(ton)
b. (BA.na)na
c. (GU.ra)su

Put differently, invoking the trochaic structure reflects a default pattern of prosodic assignment of Tokyo Japanese in general, which indicates unification of the native and loanword patterns. A similar observation has been made by Shinohara (2000, 2004) with respect to the accommodation of French words into Japanese. While in French, accent location is typically viewed as being on the final syllable of the word or phrase, the location of the accent on the borrowed words into Japanese follows the same general pattern that emerges from the trochaic foot structure.

Recall that Kubozono claims that the essence of McCawley's generalization resides in the accent pattern of the most frequent accented native nouns. He further alludes that such a correlation has to do with the fact that stress in English has as its direct manifestation a fall in pitch; that is, prosodic prominence in the source language is preserved in the loanword by accentedness, albeit on a default location. This explanation may indicate that the source language plays a role in the prosody assignment in Japanese loanwords. However, we maintain the opposite position that the source language does not play a role, primarily based on Japanese adaptation

12. An anonymous reviewer asks about those loanwords that are accentless. While the vast majority of loanwords are assigned accent in accordance with the observation of McCawley (1968) noted above (see Kubozono 2006 and references cited therein for exemplification), words such as 'America' and 'macaroni' are borrowed as accentless (i.e. they have no pitch fall). Kubozono (2011) discusses such exceptions in detail and observes that many of the accentless loanwords consist of a string of light syllables. He shows this corresponds to a tendency of accentless native Japanese words (nouns) to consist of sequences of light syllables. We view this parallelism as adding further support that the prosody assignment in loanwords follows the pattern that is already available in the borrowing language. 
from French. As Shinohara convincingly demonstrates, words in French, which basically do not manifest a pitch fall, are adapted into Japanese with an accentuation pattern very similar to English-based loanwords. That is, even when a source language does not have a suprasegmental mechanism to mark prominence in a word, it is nevertheless borrowed into Japanese with accent on it. We take this to be evidence that the suprasegmental system of a source language is not taken into consideration in Japanese loanword prosody. A summary of the factors that are relevant to our taxonomy is given in (15).

(15) a. The prosodic system of the source language does not play a role. [-SL]

b. The prosody assignment to loanwords follows the most frequent (accented) native prosodic pattern, and is not specific to loanwords. [-sp-loan]

c. Suprasegmental, and not segmental, features play a role. [+pros]

\section{English loanwords in North Kyungsang Korean (NKK)}

The next case that we consider is the adaptation of English words into North Kyungsang Korean (NKK), a pitch accent language. The loanword phonology of NKK has been detailed by Kenstowicz and Sohn (2001) and Kim (2009), and we base our discussion on these works. In the lexical accent patterns of NKK, a syllable with high pitch is considered to be accented. Most words have only one high pitch. In addition, there is a class of words that are referred to as double accent; these words have high pitch on the first two syllables with low pitch on any following syllable. Accent is lexically indicated on specific syllables. The possible accent locations in NKK are the following: final, penult, antepenult, and double (i.e. a high pitch falls on each of the first two syllables of a word). The accent patterns for native NKK words shown in (16) are lexicalized and not predictable. Some examples are presented in (17). (Note that as indicated in (16), monosyllabic words fall into two classes: the double accent class where a suffix appears with high pitch, and the final accent class where a suffix appears with low pitch. The suffixal tones are indicated in parentheses.)

(16) Native lexical tone prosody patterns in NKK ( $\mathrm{H}$ tone $=$ accented syllable $)$ (Kim, 2009)

\begin{tabular}{|l|l|l|l|l|}
\hline & Double Accent & Antepenultimate & Penultimate & Final \\
\hline 1 syllable words & H $(+\mathrm{H})$ & & & H $(+\mathrm{L})$ \\
\hline 2 syllable words & HH & & HL & LH \\
\hline 3 syllable words & HHL & HLL & LHL & LLH \\
\hline 4 syllable words & & & LLHL & \\
\hline
\end{tabular}


(17) Accent classes in NKK native words (syllables with high tone are in Italics and also indicated with the acute accent mark)
a. Double Accent: ó.ré.pi ('older brother'); kó:.kú.ma ('sweet potato')
b. Antepenult: mé.nu.ri ('daughter-in-law'); tók.su.li ('eagle')
c. Penult: a.cu.pá.nim ('elder brother-in-law'); kúk.s'i ('noodle'); cam.cá.ri ('dragonfly')
d. Final: wə.nə.mín ('native speaker'); nem.pí ('pot'); na.múl ('vegetable')
e. monosyllabic double: múl / múr-í ('water')
f. monosyllabic high: súl / súr-i ('wine')

There are several important generalizations. First, a word must have a high tone; consequently, a word can only begin in a sequence of low tones if it contains at least three syllables. Second, while most words have only one high tone, if a word has two high tones (i.e. in the double class), they must be adjacent. Third, no word can have more than two high tones. Finally, syllable weight (CV vs. CVC) does not affect high tone (accent) location in native words except that long vowels (which can only occur in initial syllables) always take high tone.

Turning to English loanwords, NKK demonstrates a case in which the location of the stress on the English word - the source language - is irrelevant to the assignment of accent class. (18) shows tonal patterns of NKK loanwords, which is somewhat different from the lexical tone patterns of NKK native words in (17). Sample loanword examples are presented in (19) with the high tone accent indicated in Italics.

(18) Loanword in NKK (Kim 2009)

\begin{tabular}{|l|l|l|l|l|}
\hline & $\begin{array}{l}\text { Double Accent } \\
\text { (Long V or CVC) }\end{array}$ & Antepenultimate & Penultimate & Final \\
\hline 1 syllable & & & & H (+ L) \\
\hline 2 syllables & HH & & HL & LH \\
\hline 3 syllables & HHL & (HLL) & LHL & LLH \\
\hline 4 syllables & HHLL & & LLHL & LLLH \\
\hline
\end{tabular}

(19) Accent classes in NKK loanwords (data from Kim 2009; Kenstowicz and Sohn 2001)

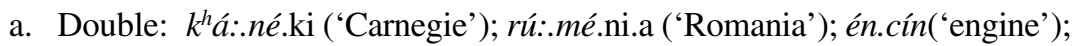
ín.tá.net ('internet'); cén.thíl.men ('gentleman'); ó:.tó ('auto')); ró:.má ('Rome')

b. Final: ri.bón ('ribbon'); pi.tha.mín ('vitamin'); mo.də.ni.jám ('modernism')

c. Penult: si.né.ma '('cinema'); a.me.rí.ka ('America'); $\mathrm{k}^{\mathrm{h}}$ a.rén.ta ('calendar'); in.p ${ }^{\mathrm{h}} \mathrm{ul}$. lu.én.ca ('influenza'); $t^{\text {hém. }} \mathrm{p}^{\mathrm{h}} \mathrm{o}$ ('tempo')

d. Antepenult: $t^{h}$ ó.si.thi ('toast')

e. monosyllabic: $t^{h} \hat{\imath}: m / t^{h} \hat{\imath}: \mathrm{m}-\mathrm{i}$ ('team/(nom.)') (*th $\left.t^{h}: m-\hat{\imath}\right)$; pú:m / pú:m-i ('boom/(nom.)') (*pú:.m-î) 
As the loanwords in (19b) and the first three examples of (19c) demonstrate, the stress pattern of English is not followed. A close examination of the examples above further reveals that the accentuation pattern on loanwords is predictable and can be viewed as comprising a system independent of the native one although closely resembling it. This is confirmed by comparing (16) and (18) that loanwords show more tonal variety for four-syllable words than native words; and, as noted by both Kenstowicz and Sohn (2001) and Kim (2009), a monosyllabic loanword cannot be in the double accent class. In loanwords, furthermore, it is generally true that heavy syllables have high tone (exceptions are predictable, as detailed in Kim 2009).

Loanwords in the double accent class (19a) always have an initial heavy syllable, which contrasts with native words as seen in (17a). Words that do not have an initial heavy syllable belong to the final accent class if their final syllable is heavy as in (19b). If the final syllable is not heavy, then the loanword will normally fall in the penultimate class as illustrated by (19c). However, if the loanword into NKK includes an epenthetic vowel in the process of adaptation, that vowel usually cannot be accented; this is illustrated by the example in (19d), where the accent is antepenultimate. The borrowed forms in (19e) exemplify the observation that a monosyllabic borrowing does not fall in the double class. This can only be observed when a suffix is added to a monosyllabic form.

There are some apparent counterexamples to these generalizations. In (19a), the final syllable of the borrowing of gentleman does not have high tone since, as observed above, no NKK word can have more than two high tones. This example shows that assignment to the double class has priority over final. On the other hand, in (19c), the borrowing of influenza does not fall in the double class despite the fact that it begins with a heavy syllable. Here, the heavy penultimate syllable in influenza requires a high tone. This precludes it from being assigned to the double class. Although these two examples illustrate conflicting priorities, they can be explained by the optimality-theoretic analysis of Kim (2009), to which we refer the reader for details.

While native words have unpredictable lexical accent, the accentuation of loanwords in NKK as discussed above is predictable in terms of syllable weight. According to Kim (2009), which builds on the work of Kenstowicz and Sohn (2001), the pattern can be captured by the assignment of weight-sensitive trochaic feet from the right edge of the word. Words in the double accent class (with two adjacent high tones) are analyzed by Kim as having two trochaic feet. Coda weight is variable depending on what makes for better footing, e.g. a CVC syllable is not always treated as heavy; it is based on the notion of contextual weight-see Rosenthall and van der Hulst 1999. There is a general constraint against two pitch falls within one word, so a borrowed word like 'America' cannot have a second foot, as shown in (20) and (21); we mark the foot with parentheses.
(20) a.
a.me(rí.ka) [L L H L]
b.
*(á.me)(rí.ka) [H L H L] 
(21)<smiles>CCCCCCCCC</smiles>

[Note: default low tone assignment produces the tone pattern L L H L]

The location of the high tone in the loanword coincides with the head of the trochaic foot. For example, the NKK borrowings of the English words America in (20)-(21) and cinema in (22a) have a penultimate high tone reflecting a right edge trochaic foot; the word 'London' in (22h) is borrowed as double accent with high tone on both syllables since the word can be parsed with two weight sensitive trochaic feet. More examples of foot structure in loanwords are presented in (22), (23), and (24).

(22) Examples of foot structure in loanwords, following Kim (2009) (Italicized consonant indicates that it is contextually moraic)

a. cinema -- si (né.ma)

b. ribbon -- ri(bón)

c. Carnegie -- (ká:)(né.ki)

d. internet -- (ín)(tó.net)

e. engine -- (én)(cín)

f. gentleman -- (cén)( $\mathrm{t}^{\mathrm{h}} \mathrm{t}$ l.men $)$

g. tempo -- $\left(\mathrm{t}^{\mathrm{h} e ́ m .} \mathrm{p}^{\mathrm{h}} \mathrm{o}\right) \mathrm{cf}$. *(thém) $\left(\mathrm{p}^{\mathrm{h}} \mathrm{o}\right)$ (this has a monomoric foot)

h. London -- (lón)(dón)

i. auto -- (ó:)(tó) cf. *(ó:to) (trimoraic parse, dispreferred to the parse in (i))

(23) Two high tones (double accent) represent two trochaic feet in the word<smiles>ICCI</smiles>

a. (kná:)(né.ki)

Carneige
b. (ín)(tó.net) internet
H H L

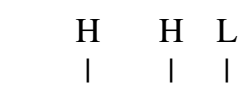

c. (cén)( th'́l.men) gentleman d. (én)(cín) engine e. ri(bón) ribbon

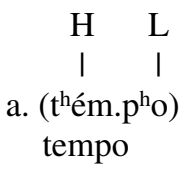<smiles>[1H]I</smiles><smiles>CCC</smiles>

b. *(thém)(p pó) tempo
c. (ó:)(tó) auto

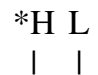

d. *(ó:.to)

One may wonder whether the metrical phonology of NKK actually serves as an underlying force for the loanword accentuation pattern that has been discussed above. While the trochaic system in (19) may reflect the emergence of the unmarked in the sense of McCarthy and Prince (1994), it would be controversial to argue that such foot structure is characteristic of native NKK words. Kenstowicz and Sohn (2001) suggest that the assignment of trochaic feet to loanwords can be 
viewed as a default mechanism more generally within NKK. Evidence for this comes from (16): native NKK words of four syllables (or longer) have penultimate accent. But even if such native words are assigned a trochaic foot by default, it is different from the loanword trochaic foot, which is sensitive to the mora. This is most clearly seen by the borrowing of the four-syllable word 'modernism' in (19b), which has a high tone on the final (bimoraic) syllable; consequently, the assignment of mora-sensitive trochaic feet seems to be unique to loanwords in NKK.

An interesting issue that emerges from the NKK loanword accentuation pattern is the absence of monosyllabic loanwords that are in the double accent class. The table in (18) and the examples in (19e) illustrate that there are no monosyllabic loanwords with a high tone that receive a second (covert) high tone when a suffix is added, e.g. $t^{h} i: m / t^{h} i: \mathrm{m}-\mathrm{i}\left({ }^{*} t^{h} i: m-\hat{\imath}\right)$. This may suggest an additional requirement that (English) loanwords have a pitch fall.

The loanword prosody in NKK is summarized in (25).

(25) a. The prosodic system of the source language does not play a role. [-SL]

b. The prosody assignment to loanwords is specific to loanwords. [+sp-loan]

c. Suprasegmental—specifically syllable weight — and not segmental features play a role. [+pros]

\section{English loanwords in South Kyungsang Korean (SKK)}

South Kyungsang Korean (SKK) is another pitch-accent language, ${ }^{13}$ which is distinct from NKK. One important way in which SKK differs from NKK is that SKK has an inviolable constraint against words beginning with low tone on the first two syllables (*\#LL). This means that a high tone must occur on either the first or second syllable of the SKK word. If a high tone is not assigned to the first syllable, it will surface on the second. In considering native SKK words, it is a lexically determined property as to whether the first syllable is assigned a high tone. It does not correlate with consonant type, syllable type, or syllable weight. The table (26) displays the native lexical prosody of monomorphemic words in SKK. Some examples are given in (27), where syllables with high tone are indicated in Italics. (We ignore the complex issue of tone on monosyllabic words; see Lee and Davis 2010 for a recent analysis. All SKK data are taken from Lee 2009.)

13. There is some controversy as to whether SKK should be described as a pitch-accent language or a tone language that contrasts high, mid, and low tones. We follow Lee (2009), Davis (2010), and Lee and Davis $(2009,2010)$ in viewing SKK as a pitch-accent language that distinguishes hightone and low-tone syllables. In addition, unlike NKK but like Japanese, SKK has both accented and unaccented high tones. See these works for argumentation. 
(26) Native lexical tone prosody in SKK

\begin{tabular}{|l|l|l|}
\hline 2 syllable words & 3 syllable words & 4 syllable words \\
\hline LH & $\begin{array}{l}\text { LHL } \\
\text { LHH }\end{array}$ & LHHL \\
\hline HL & HLL & \\
\hline HH & HHL & HHLL \\
\hline
\end{tabular}

(27) a. ku.rim $(\mathrm{HH})$ 'clouds'

b. ki.rim (HL) 'oil'

c. kə.rim (LH) 'fertilizer'

d. o.re.pi (HHL) 'elder brother'

e. a.cu.mə.ni (LHHL) 'aunt'

f. non.tu.rəy (LHH) 'rice-field levee'

g. a.ci.me (HLL) 'aunt'

Turning to the assignment of prosody on English loanwords in SKK, an important question is whether high tone is assigned to the first syllable or to the second. The borrowing of words like America and vitamin, which begins with a sequence of low tones in NKK (i.e. [a.me.rí.ka] and [pi.tha.mín]), has to be realized with a high tone on (at least) one of the first two syllables in order to avoid a violation of the *\#LL constraint. With this in mind, let us consider the examples in (28) of English loanwords.

(28) English loanwords in SKK (Lee 2009)
a. $\mathrm{k}^{\mathrm{h}} \mathrm{e} . p i . n e \mathrm{t}$
(L H HL) 'cabinet'
b. si.sti.them
(L H HL) 'system»'
c. o.ren.ci
(L H L) 'orange'
d. $k^{h} e m \cdot p^{h} \partial . s_{1}$
(H H L) 'campus'
e. men. fan
(H HL)
'mansion'
f. kol.p $\mathrm{p}^{\mathrm{h}} \mathbf{\mathrm { i }}$
(H L)
'golf'
g. in.ti.a.na
(H H H L) 'Indiana'
h. sen.ti.wi.t $\int 1$
(H H H L) 'sandwich'
i. a.me.ri.ka
(L H H L) 'America'
j. ma.ki.ne./jum
(L H H H L) 'magnesium'
k. $k^{h}$ on.sen. $\mathrm{t}^{\mathrm{h}} \mathrm{i}^{\mathrm{i}}$
(H H L)
'consent'
1. te.mo
(H L)
'demo' 
Unlike with native words, there is a consistent pattern as to how high tone is assigned either to the first or second syllable of the loanwords. Moreover, the loanword tone assignment on the entire word displays a predictable pattern. Following Lee (2009), we maintain that the prosodic pattern assigned to a loanword is determined by the weight of the first syllable. If the initial syllable is borrowed as light, then it has low tone; all subsequent syllables have high tone except for the final mora of the word, which always takes a low tone (Kubozono 2007). But, if the initial syllable is heavy, then it has a high tone; all following syllables also take high tone(s) except for a word-final mora. One regular exception to this pattern is shown in (281), the borrowing of the word demo. ${ }^{14}$ If a borrowed word consists of two light syllables, the first one is assigned a high tone; a word like demo could not surface with two low tones because it would violate the *\#LL constraint.

The data in (28) illustrate a clear pattern that tone assignment to English loanwords in SKK is dependent on the weight of the initial syllable. We argue that this assignment does not reflect any properties of the source form. It is evident that source stress location is ignored. This is most clearly seen from the borrowing of cabinet in (28a) and consent in (28k). Since main stress on the English word cabinet is on the initial syllable, that syllable would have the highest pitch in the English form (at least in its citation form). But the initial syllable in the borrowed form $/ \mathrm{k}^{\mathrm{h}}$ e.pi.net/ has low tone. This is because the initial syllable comprises a light syllable. On the other hand, in the borrowed form consent in (28k), the initial syllable is borrowed with a high tone even though in the English source, it would have a lower pitch than the second syllable, which has primary stress. The initial syllable has high tone since it is borrowed as a heavy syllable. Moreover, syllable weight is determined by its syllabification not in the source language but in SKK. This is demonstrated in (28j) for the borrowing of magnesium. The English initial syllable is heavy while it is realized as light in SKK because of vowel epenthesis. The low tone assignment to the initial syllable of the SKK form indicates that it is the weight of the SKK syllable and not the source syllable that matters. Furthermore, as the example in (28a) shows, the laryngeal feature of the initial consonant of the source word does not affect tone assignment. The word cabinet in (28a) begins with an aspirated consonant. It is well-known that in both English and Korean, aspirated consonants are phonetically associated with slightly higher pitch on the following vowel. We have also seen from the discussion of Lhasa Tibetan that source laryngeal features can play a role in tone assignment to borrowed forms. Nonetheless, SKK ignores the correlation between aspiration and higher pitch and assigns low tone to the initial syllable of the borrowing cabinet. It is syllable weight of the borrowing language that serves as the determining factor. ${ }^{15}$ Consequently, we see that

14. There are other exceptions to the weight-sensitive tone assignment, but most, although not all, of these exceptions are systematic. For example, syllables closed with a geminate lateral are always treated as light. See Lee (2009) for details and an optimality-theoretic analysis of loanword tone assignment.

15. We should note that some instances of aspiration on an initial consonant in the English source word seem to affect the assignment of high tone in the SKK borrowing. These cases involve disyllabic loanwords in which the initial syllable is light and the second syllable is heavy. While Lee (2009) 
characteristics in the source language are ignored in the assignment of prosody to loanwords in SKK. Instead, respecting the inviolable constraint of *\#LL plays a crucial role in the loanword prosody assignment in this language. Syllable weight is the language-specific mechanism used to assign the initial tone.

Any attempt to explain what underlies the motivation for the use of syllable weight for determining initial tone assignment remains just conjecture at this time. Perhaps, native SKK words like those in (27) have covert lexically indicated iambic feet, and these emerge initially in loanwords. However, there does not seem to be independent evidence for iambic foot structure outside the system of loanword prosody. One may also consider that the high tone on an initial heavy syllable in loanwords reflects frequency biases in native words. But such a bias, were it to exist, would itself need an explanation. Moreover, it would not account for the overall tone pattern for loanwords where low tone always occurs on a final syllable (mora). Although it is yet to be confirmed, our suggestion is that the weightsensitive assignment of high tone onto the first heavy syllable, or otherwise to the second syllable of the loanword, has as its underlying motivation the phonologization of phrasal intonation. Various researchers (e.g. Park 2003) have shown that a phrasal high is often associated with the second mora of the Korean phrase. It is possible that phonologization of this phrasal high takes place in the SKK loanword as a ready means of assigning a tone height to the borrowed form. If the initial syllable is bimoraic, the phrasal high occurs on that syllable; if it is monomoraic, the initial syllable is assigned a low tone, with the high tone on the second syllable, thus resembling an iambic system. Such a strategy would be phonological and not just taken straightforward from the phonetics, because it has been widely discussed that the occurrence of marked laryngeal features in Korean (i.e. aspiration and tenseness) correlate with high tone and that an initial syllable with such a feature would receive a phrasal high tone even if it is monomoraic (see Jun 1993 for standard Korean and Park 2003 for Chonnam Korean). Laryngeal features have little effect on tone assignment in SKK loanwords. Furthermore, the phonologization of phrasal intonation could also offer an explanation for the overall tone pattern on the loanwords in (28), all of which have a low tone on the final mora. As Utsugi (2009) notes, SKK varieties have a boundary low tone that is witnessed on words that end in a high tone. If phrasal intonation were phonologized, we would expect loanwords to end in a low tone at the word level. The result of phonologization of phrasal intonation would be word intonation very much like what we see on the loanwords in (28).

(29) summarizes the properties of SKK loan prosody.

reports that 189 out of 207 such loanwords have the expected low tone on the initial syllable, Jun (2006) has observed that there are examples where high tone is nonetheless assigned to the light initial syllable if it begins with an aspirated consonant. Such examples include the borrowings of 'puzzle' and 'comic'. We take this to be a minor variation that affects just this subgroup of loanwords. It reflects the phonetic relationship that exists between aspiration and high pitch in both English source words and native SKK words. 
(29) a. The prosodic system of the source language does not play a role. [-SL]

b. The prosody assignment to loanwords is specific to loanwords. [+sp-loan]

c. Suprasegmental—specifically syllable weight—and not segmental, features play a role. [+pros]

While the properties summarized in (29) for SKK resemble those for NKK in (28), one difference between the two that is not indicated is the priority in SKK of assigning a high tone to the left edge of the word in order not to violate the *\#LL constraint. Such a constraint, in contrast, does not play a role in NKK tonology.

\section{Summary and discussion}

We have surveyed various patterns in which prosody is adapted onto loanwords in a borrowing language. The summary of our discussion is given in terms of our proposed taxonomy in (30). Loanword Prosody

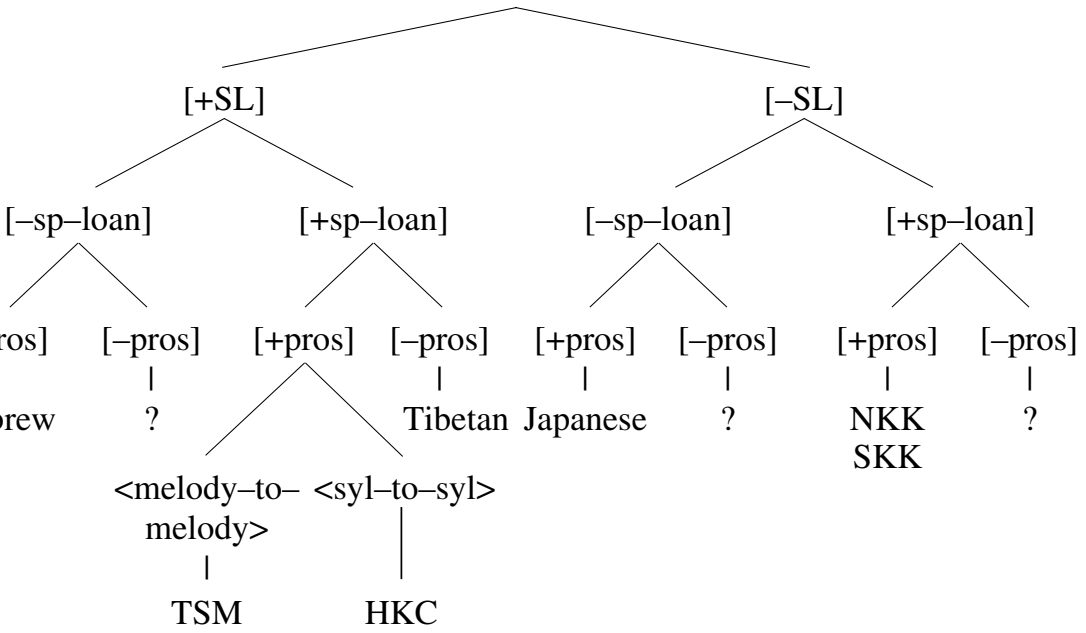

[+/-SL]: [+/-source language]

[+/-sp-loan]: [+/-specific to loanwords]

[+/-pros]: [+/-prosody]

HKC: Hong Kong Cantonese

TSM: Taiwanese Southern Min

NKK: North Kyungsang Korean

SKK: South Kyungsang Korean 
The first main division of our taxonomy is whether properties of a source language are attended to in loanword adaptation. Within each of these divisions, [+SL] vs. [-SL], we make a further split as to whether the assignment of prosody reflects a strategy that is specific to loanwords, [+sp-loan], or is based on factors that can be seen elsewhere in the borrowing language, [-sp-loan]. A further division is made as to whether the strategy references prosodic ([+pros]) or segmental ([-pros]) features. While we mapped our seven languages onto the taxonomy in (30), there are other types of languages that might fill in the gaps, as indicated by «?». For instance, according to Silva (2006), Seoul Korean is currently developing a tonal contrast in such a way that a syllable beginning with an aspirated consonant is assigned high tone while one that starts with a lax (voiced) obstruent receives low tone. If this contrast applies to loanwords, as we suspect it would, then the loanword prosody in Seoul Korean would naturally fit the class of \{[+SL], [-sp-loan], [-pros] $\}$. On the other hand, there are many more language examples to be added to the taxonomy in (30). Finnish, for one, would join Japanese as falling under the class of $\{[-\mathrm{SL}]$, [-sp-loan], [+pros]\}: as Kang (2010) mentions, Finnish has regular word-initial primary stress, which is also adopted by loanword prosody. That is, regardless of the location of the stress in a source language, the stress pattern of loanwords is consistent with that of native Finnish words.

A further question that awaits an extensive investigation revolves around the case of multiple source languages. In discussing Lhasa Tibetan, we noted that Mandarin and English words are borrowed through an essentially identical prosodic adaptation mechanism. Similarly, Lee (2009) shows that Japanese words have the same adaptation pattern with English words in SKK loanwords. In contrast, the prosodic features of Japanese and Mandarin Chinese take different paths in prosodic adaptation into Yanbian Korean (Ito and Kenstowicz 2009), where source prosody is important for the Mandarin, but not Japanese, borrowings. Furthermore, we informally observe that a large bulk of Japanese words borrowed into English takes the penultimate stress pattern. For example, loanwords like karaóke, sashimi, and wasábi, do not maintain the location of the source accent (accentless, final, and initial, respectively). This is contrasted with French-based loanwords in English, which often keep the word-final stress, as garáge, buffét, and champágne. These observations ultimately lead to an interesting question as to what are underlying factors that determine whether the prosodic properties of a source language are taken into consideration. As is suggested by Kang (2010), a high degree of bilingualism between the two languages, for one, may be a key factor for favoring preservation of the source prosody in some way.

Another question has to do with the nature of [+sp-loan]. As a result of our discussion, we have identified Lhasa Tibetan and SKK as sharing the classification of [+sp-loan]. These two languages are also similar in that the determination of the first syllable being assigned a high tone is crucial for the loanword prosody; however, the exact nature of the mechanism is very different, i.e. sensitive to the segmental nature (Tibetan) or to syllable weight (SKK). Other cases of loanword-specific mechanisms for the assignment of prosody that have been discussed in the literature include the complex mapping of syllable and segment 
type to tone found with English borrowings into White Hmong (Golston and Yang 2001), and post-stress phoneme truncation found with Spanish loanwords into Huave (Davidson and Noyer 1997). Given that the mechanisms leading to [+sp-loan] are not found anywhere in the synchronic system internal to the borrowing language, we would need to investigate as to where they originate from, if such a source were to be found at all. The notion of «the emergence of the unmarked» as well as potential diachronic influences may well lead us to possible answers to this question.

Finally, we note that there may be interesting differences among languages that share the characteristic of [-sp-loan]. In comparing prosodic adaptation between Japanese and Modern Hebrew-both [-sp-loan] — the most frequent accent pattern serves as a crucial factor in Japanese while an infrequent and noncanonical class (i.e. the immobile class) plays a role in Hebrew nouns. It would be intriguing to find out why such a contrastive situation exists. Moreover, the Hebrew pattern of immobile stress on loanwords in (6) is revealed only by considering the borrowed noun in a paradigm (e.g. singular-plural pairs). Although the role of paradigms in loanword phonology needs to be further explored, preliminary work such as Simonović (to appear) suggests a tendency across a paradigm for uniformity of accent location in loanwords.

While we have concluded our discussion with the taxonomy in (30), it is evident that there are other potential ways in which a taxonomy can be organized. We have made a major division first on [+/-SL] and then on [+/-sp-loan], but these labels could well be reversed. As more languages are surveyed regarding loanword prosody adaptation, some other classificatory terms may emerge. Admittedly, further research should be conducted for a fuller and accurate taxonomy of loanword prosody, but we hope that our proposed taxonomy in (30) can serve as a foundation for future exploration on this topic.

\section{Acknowledgement}

Aspects of our work on loanword prosody have been discussed with Outi Bat-El, Michael Becker, Zhuting Chang, Ken de Jong, Daniel Dinnsen, Tracy Alan Hall, René Kager, Yoonjung Kang, Dov-Ber Kerler, Jungsun Kim, Björn Köhnlein, Haruo Kubozono, Dongmyung Lee, and Marko Simonović. A preliminary version of this paper was presented by the first author at the International Conference on Phonetics and Phonology held December 10-14, 2011 in Kyoto, Japan. We thank the participants of the conference for their comments. We also thank Michael Kenstowicz and the anonymous reviewers for their valuable suggestions. 


\section{References}

Altmann, Heidi (2006). «The Perception of L2 Stress». Poster presented at 14th Manchester Phonology Meeting, May 25-27.

Bat-El, Outi (1994). «Stem Modification and Cluster Transfer in Modern Hebrew». Natural Language and Linguistic Theory 12: 571-596.

Bat-El, Outi (1996). «Selecting the Best of the Worst: The Grammar of Hebrew Blends». Phonology 13: 283-328.

Bat-El, Outi (2005). «The Emergence of the Trochaic Foot in Hebrew Hypocoristics». Phonology 22: 115-143.

Bauer, Robert; Benedict, Paul (1997). Modern Cantonese Phonology. New York: Mouton de Gruyter.

Becker, Michael (2003). «Lexical Stratification in Hebrew - The Disyllabic Maximum». Proceedings of the Israeli Association of Theoretical Linguistics. Available at: http://atar.mscc.huji.ac.il/ english/IATL/19/TOC.html

Broselow, Ellen (2009). «Stress Adaptation in Loanword Phonology: Perception and Learnability». In: Boersma, Paul and Hamann, Silke (eds.). Phonology in Perception. Berlin: Mouton de Gruyter, pp. 191-243.

Chen, Matthew (1987). «The Syntax of Xiamen Tone Sandhi». Phonology Yearbook 4: 109-149.

Cheng, Robert Liang-wei (1979). Regularity of Sound Correspondences in Taiwanese and Mandarin (Taiyu yu guoyu ziyin duiyin guilu de yanjiu) [in Chinese]: Monographs on Modern Linguistics. Taipei: Taiwan students' Press.

Chung, Raung-fu (1996). The Segmental Phonology of Southern Min in Taiwan. Taipei: The Crane Publishing Company.

Cutler, Anne (2005). «Lexical Stress». In: Pisoni, David; Remez, Robert (eds.), The Handbook of Speech Perception. Oxford: Blackwell, pp. 264-289.

Davidson, Lisa; Noyer, Ralph (1997). «Loan Phonology in Huave: Nativization and the Ranking of Faithfulness Constraints». WCCFL 15: 65-79.

Davis, Stuart (2010). «A Note on the Loanword Tonology of Kyungsang Korean Dialects». In: Lee, Sang-Oak (ed.). Contemporary Korean Linguistics: International Perspectives. Gyeonggi, Korea: Thaehaksa Publishing Co., pp. 46-62.

Golston, Chris; Yang, Phong (2001). «Hmong Loanword Phonology». HILP 12: 40-57.

Graf, Dafna; Ussishkin, Adam (2003). «Emergent Iambs: Stress in Modern Hebrew». Lingua 113: 239-270.

Hao, Yen-Chen. (2009). «Tonal Adaptation of English Loanwords in Cantonese». In: Xiao, Yun (ed.). Proceedings of the 21st North American Conference on Chinese Linguistics (NACCL-21). Smithfield, Rhode Island: Bryant University, pp. 42-54.

Haraguchi, Shosuke (1977). The Tone Pattern of Japanese: An Autosegmental Theory of Tonology. Tokyo: Kaitakusha.

Hombert, Jean-Marie; Ohala, John; Ewan, William (1979). «Phonetic Explanation for the Development of Tone». Language 55: 37-58.

Hsieh, Feng-fan (2006). «High Infidelity: The Non-mapping of Japanese Accent onto Taiwanese Tone». In: Hsieh, Feng-fan; Kenstowicz, Michael (eds.). Studies in Loanword Phonology, MIT Working Papers in Linguistics 52. Cambridge: Department of Linguistics and Philosophy, MIT, pp. 1-27. 
Hsieh, Feng-fan; Kenstowicz, Michael (2008). «Phonetic Knowledge in Tonal Adaptation: Chinese and English Loanwords into Tibetan». Journal of East Asian Linguistics 17: 279-297.

Hyman, Larry (2006). «Word-prosody Typology». Phonology 23: 225-257.

Ito, Chiyuki; Kenstowicz, Michael (2009). «Mandarin Loanwords in Yanbian Korean II: Tones». Language Research 45: 85-109.

Jun, Ho-Kyung (2006) «Factors Affecting Accentual patterns of Loanwords in Pusan Korean». Harvard Studies in Korean Linguistics 11: 158-70.

Jun, Sun-Ah (1993). The Phonetics and Phonology of Korean Prosody. Doctoral dissertation, The Ohio State University.

Kang, Yoonjung (2010). «Tutorial Overview: Suprasegmental Adaptation in Loanwords». Lingua 120: 2295-2310.

Kang, Yoonjung (2011). «Loanword Phonology». In: van Oostendorp, Marc; Ewen, Colin; Hume, Elizabeth; Rice, Keren (eds.). Companion to Phonology. Malden, MA: Wiley-Blackwell, pp. 2258-2282.

Kenstowicz, Michael; Sohn, Hyang-Sook (2001). «Accentual Adaptation in North Kyungsang Korean». In: Kenstowicz, Michael (ed.). Ken Hale: A Life in Language. Cambridge, MA: MIT Press, pp. 239-270.

Kim, Jungsun (2009). «Double Accent in Loanwords of North Kyungsang Korean and Variable Syllable Weight». Language Research 41: 67-83.

Kingston, John (2011). «Tonogenesis». In: van Oostendorp, Marc; Ewen, Colin; Hume, Elizabeth; Rice, Keren (eds.). Companion to Phonology. Malden, MA: WileyBlackwell, pp. 2304-2333.

Kingston, John; Diehl, Randy (1994). «Phonetic Knowledge». Language 70: 419-454.

Kiu, K.L. (1977). «Tonal Rules for English Loanwords in Cantonese». Journal of the International Phonetic Association 7: 17-12.

Kubozono, Haruo (2006). «Where Does Loanword Prosody Come From? A Case Study of Japanese Loanword Accent». Lingua 116: 1140-1170.

Kubozono, Haruo (2007). «Loanword Accent in South Kyungsang Korean: A Moraic Account». ICPhS XVI: 1185-1188.

Kubozono, Haruo (2011). «Japanese Pitch Accent». In: van Oostendorp, Marc; Ewen, Colin; Hume, Elizabeth; Rice, Keren (eds.). Companion to Phonology. Malden, MA: Wiley-Blackwell, pp. 2879-2907.

Lee, Dongmyung (2005). «Weight-sensitive Tone Patterns in Loanwords of South Kyungsang Korean». BLS 31: 229-240.

Lee, Dongmyung (2009). The Loanword Tonology of South Kyungsang Korean. Indiana University, doctoral dissertation.

Lee, Dongmyung; Davis, Stuart (2009). «On the Pitch-Accent System of South Kyungsang Korean: A Phonological Perspective». Language Research 45: 3-22.

Lee, Dongmyung; Davis, Stuart (2010). «Evidence for Accentless Words in South Kyungsang Korean». Studies in Phonetics, Phonology and Morphology 16: 245-258.

McCarthy, John; Prince, Alan (1994). «The Emergence of the Unmarked». NELS 24: 333-379.

McCawley, James (1968). The Phonological Component of a Grammar of Japanese. The Hague: Mouton.

Park, Kwang Chul (2003). Initial Segmental and Phrasal Tones in the Korean Dialects. Indiana University, doctoral dissertation. 
Rosenthall, Sam; van der Hulst, Harry (1999). «Weight-by-position by Position». Natural Language and Linguistic Theory». 17: 499-540.

Shinohara, Shigeko (2000). «Default Accentuation and Foot Structure in Japanese: Evidence from Japanese Adaptations of French Words». Journal of East Asian Linguistics 9: 55-96.

Shinohara, Shigeko (2004). «Emergence of Universal Grammar in Foreign Word Adaptations». In: Kager, René; Pater, Joe; Zonneveld, Wim (eds.). Constraints in Phonological Acquisition. Cambridge: Cambridge University Press, pp. 292-320.

Silva, David (2006). «Acoustic Evidence for the Emergence of Tonal Contrast in Contemporary Korean». Phonology 23: 287-306.

Silverman, Daniel (1992). «Multiple Scansion in Loanword Phonology: Evidence from Cantonese». Phonology 9: 289-328.

Simonović, Marko (to appear). «The Emergence of Post-cyclic Prosody in Loanword Integration: Toneless Latinate Adjectives in Serbo-Croatian». Acta Linguistica Hungarica 59.

Tu, Jung-yueh (forthcoming). Word Prosody in Loanword Phonology: Focus on Japanese Borrowings into Taiwanese Southern Min. Indiana University, doctoral dissertation.

Tu, Jung-yueh; Davis, Stuart (2009). «Japanese Loanwords into Taiwanese Southern Min». In Proceedings of the Second International Conference on East Asian Linguistics. Simon Fraser University. Available online at: http://www.sfu.ca/gradlings/wp2.html

Ussishkin, Adam (1999). «The Inadequacy of the Consonantal Root: Modern Hebrew Denominal Verbs and Output-Output Correspondence». Phonology 16: 401-442.

Utsugi, Akira (2009). «Merger-in-progress of Tonal Classes in Masan/Changwon Korean». Language Research 45: 23-42.

Yip, Moira (1993). «Cantonese Loanword Phonology and Optimality Theory». Journal of East Asian Linguistics 2: 261-291.

Yu, Alan C. L. (2007). «Understanding Near Mergers: The Case of Morphological Tone in Cantonese». Phonology 24:187-214.

Zhang, Jie (1998). «Checked Tones in Chinese Dialects: Evidence for Phonetically Driven Phonology». CLS 34: 439-453.

Zuckermann, Ghil'ad (2003). Language Contact and Lexical Enrichment in Israeli Hebrew. New York: Palgrave Macmillan. 